\title{
Smart Hydrogel Grating Immunosensors for Highly Selective and Sensitive Detection of Human-IgG
}

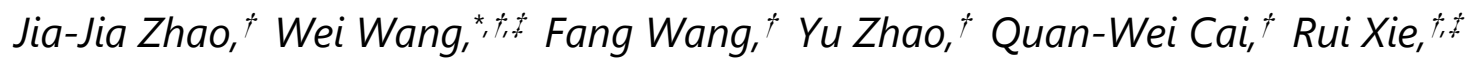

Xiao-Jie Ju, t,t Zhuang Liu, t,t Yousef Faraj, t,t and Liang-Yin Chu, ${ }^{*}, t$

†School of Chemical Engineering, Sichuan University, Chengdu, Sichuan 610065, China

¥State Key Laboratory of Polymer Materials Engineering, Sichuan University, Chengdu, Sichuan 610065, China

${ }^{*}$ Corresponding Authors. E-mail: chuly@scu.edu.cn (L.-Y. $\quad$ C.), wangwei512@scu.edu.cn (W.W.) 


\section{Supplementary Figures S1-S3}
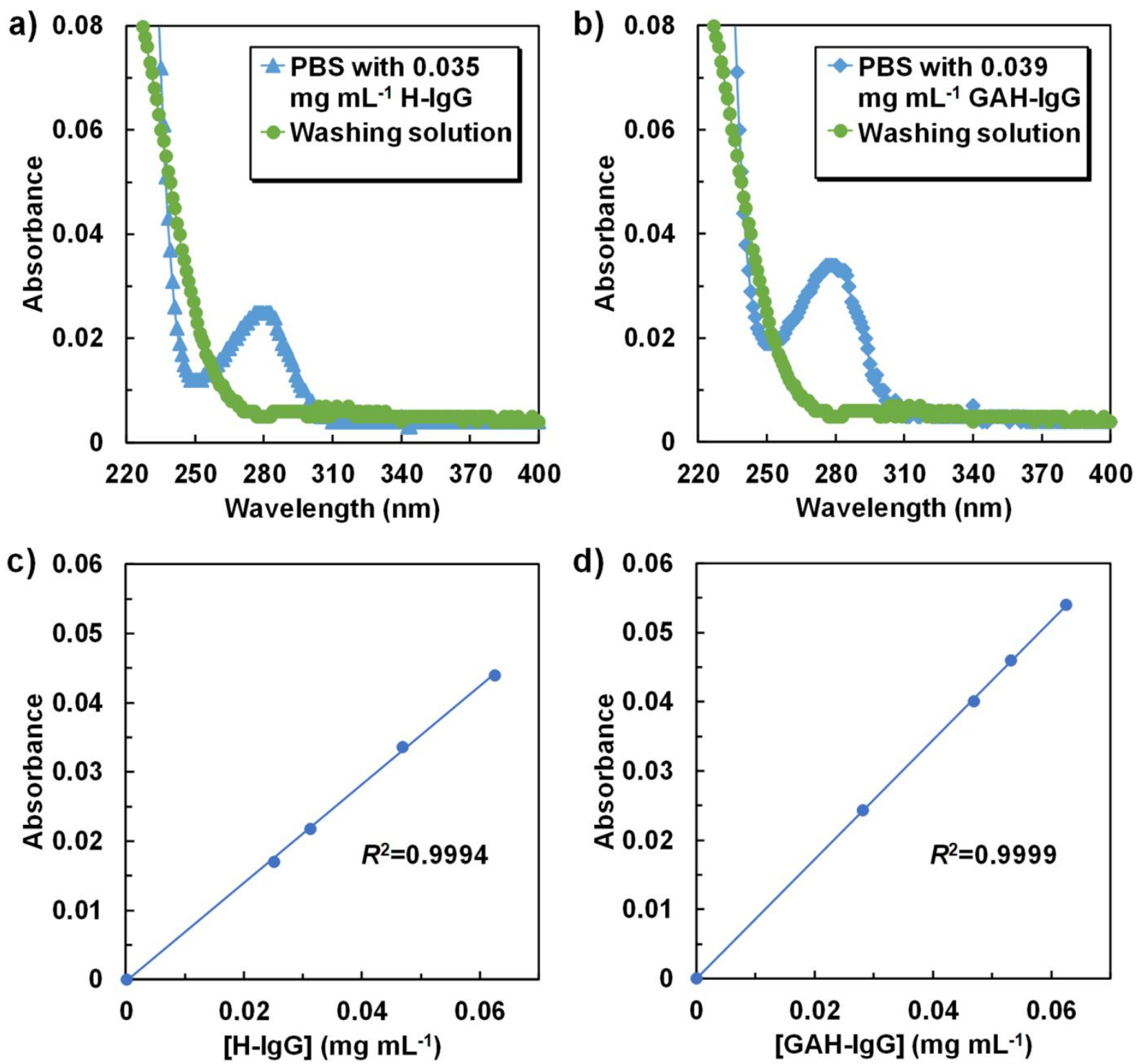

Figure S1. UV analyses of washing solutions from affinity chromatography. (a) UV analysis of washing solution and PBS solution with $0.035 \mathrm{mg} \mathrm{mL}^{-1} \mathrm{H}-\mathrm{IgG}$. (b) UV analysis of washing solution and PBS with $0.039 \mathrm{mg} \mathrm{mL}^{-1}$ GAH-IgG. (c,d) Calibration curves for H-IgG (c) and GAH-IgG (d). The results indicate that $\sim 93 \%$ of $\mathrm{H}-\operatorname{IgG}$ are polymerized into the hydrogel grating. 


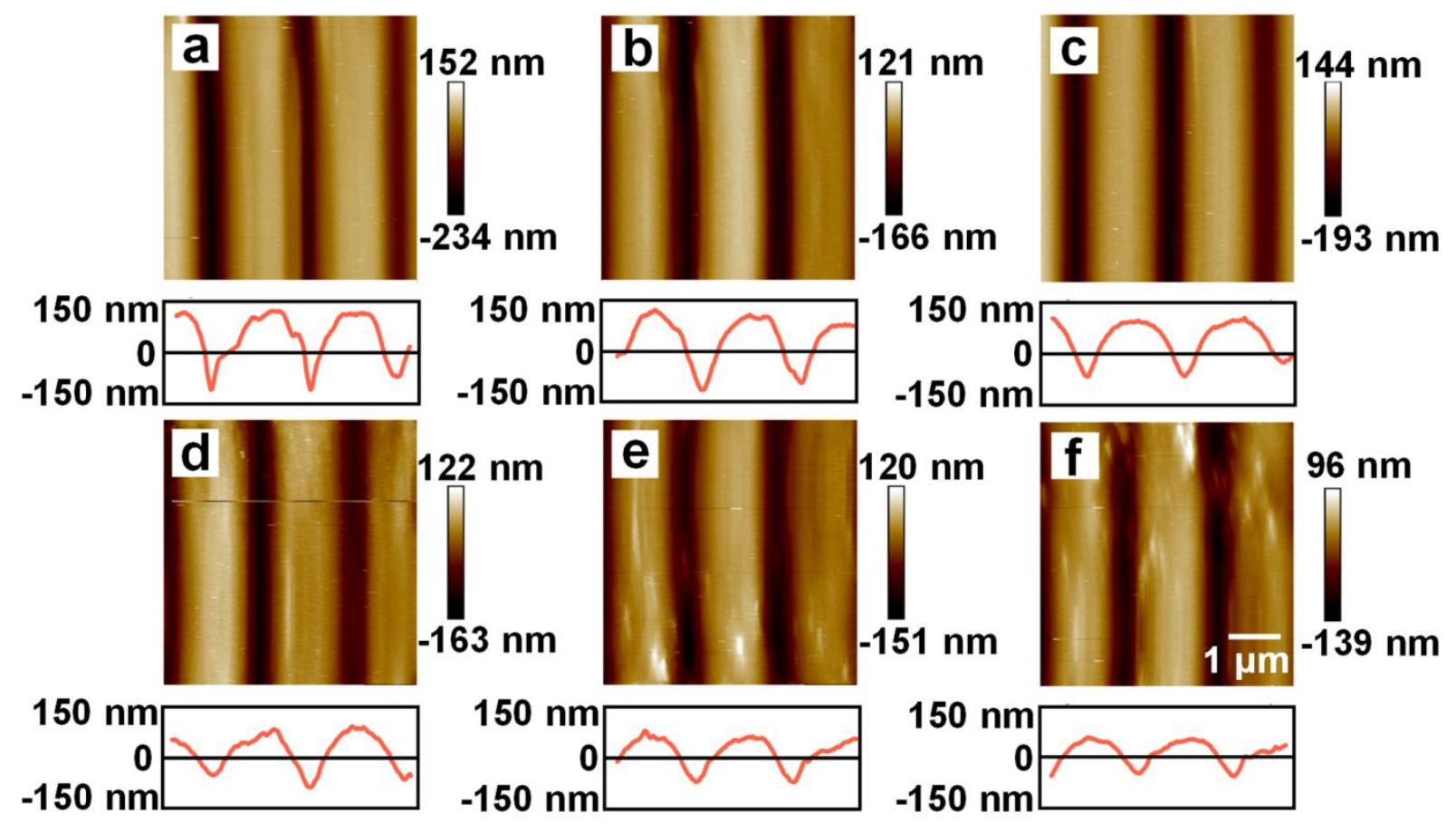

Figure S2. AFM analyses of hydrated hydrogel gratings at $25^{\circ} \mathrm{C}(\mathrm{a}), 30^{\circ} \mathrm{C}(\mathrm{b}), 35^{\circ} \mathrm{C}(\mathrm{c})$, $40{ }^{\circ} \mathrm{C}(\mathrm{d}), 45^{\circ} \mathrm{C}(\mathrm{e})$, and $50{ }^{\circ} \mathrm{C}(\mathrm{f})$. 


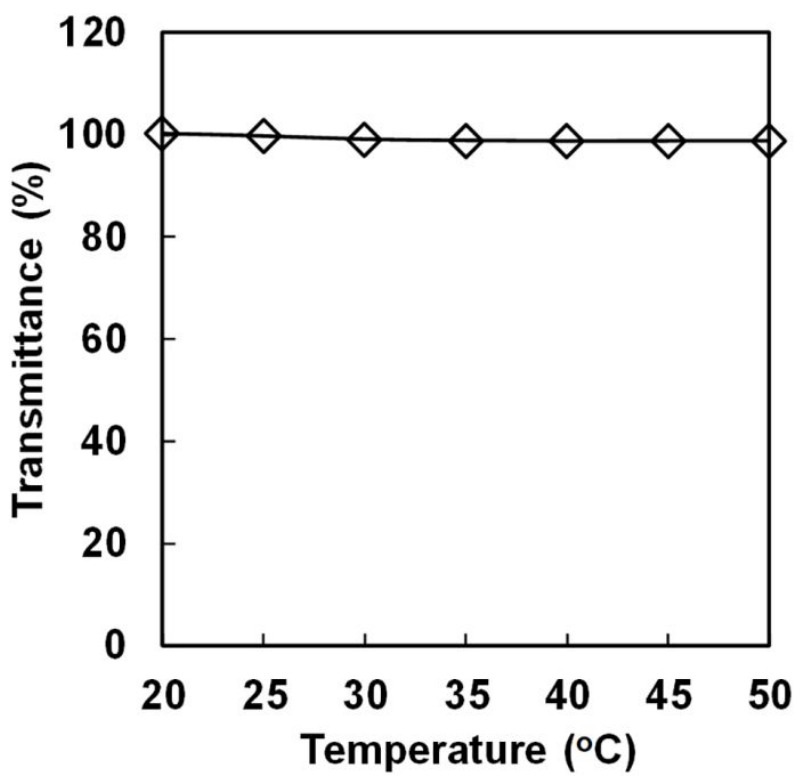

Figure S3. Transmittance of hydrogel grating at different temperatures. 


\section{Supplementary Table S1}

Table S1. Comparison of performances of different optical immunosensors for detection of H-IgG

\begin{tabular}{|c|c|c|c|c|}
\hline Types & Sensor element & Linear range & Detection limit & Ref. \\
\hline \multirow[t]{3}{*}{$\begin{array}{l}\text { Optical fiber } \\
\text { immunosensors }\end{array}$} & $\begin{array}{l}\text { Protein A-modified } \\
\text { near-infrared fluorescent } \\
\text { single-walled carbon nanotube }\end{array}$ & $\begin{array}{l}0.001 \sim 100 \mu \mathrm{g} \\
\mathrm{mL}^{-1}\end{array}$ & $10 \mathrm{ng} \mathrm{mL}^{-1}$ & {$[\mathrm{~S} 1]$} \\
\hline & $\begin{array}{l}\text { Protein A and goat anti-H-IgG } \\
\text { covalently immobilized on } \\
\text { standard single mode fiber }\end{array}$ & $\begin{array}{l}0.5 \sim 5 \mu \mathrm{g} \\
\mathrm{mL}^{-1}\end{array}$ & $47 \mathrm{ng} \mathrm{mL}^{-1}$ & {$[\mathrm{~S} 2]$} \\
\hline & $\begin{array}{l}\text { Polyimide-Mach-Zehnder } \\
\text { interferometric sensors } \\
\text { modified with Streptavidin and } \\
\text { biotinylated anti-H-IgG }\end{array}$ & $5 \sim 200 \mathrm{nM}$ & $100 \mathrm{pM}$ & {$[\mathrm{S} 3]$} \\
\hline \multirow{4}{*}{$\begin{array}{l}\text { Surface } \\
\text { plasmon } \\
\text { resonance } \\
\text { immunosensors }\end{array}$} & $\begin{array}{l}\text { Graphene oxide/silver coated } \\
\text { polymer cladding silica fiber }\end{array}$ & $\begin{array}{l}5 \sim 100 \mu \mathrm{g} \\
\mathrm{mL}^{-1}\end{array}$ & $0.04 \mu \mathrm{g} \mathrm{mL}^{-1}$ & {$[\mathrm{~S} 4]$} \\
\hline & $\begin{array}{l}\text { Multiplexed gold nanorod } \\
\text { arrays in biochip }\end{array}$ & $10 \sim 60 \mathrm{nM}$ & $10 \mathrm{nM}$ & {$[\mathrm{S} 5]$} \\
\hline & $\begin{array}{l}\text { Polydopamine-modified } \\
\text { electroless-plated gold film }\end{array}$ & $\begin{array}{l}2 \sim 100 \mu \mathrm{g} \\
\mathrm{mL}^{-1}\end{array}$ & $2 \mathrm{ug} \mathrm{mL}-1$ & {$[\mathrm{~S} 6]$} \\
\hline & $\begin{array}{l}\text { Self-assembled monolayers of } \\
\text { branched-amine-coupled } \\
\text { alkanethiol on planar surfaces }\end{array}$ & $\begin{array}{l}0.005 \sim 5 \mathrm{mg} \\
\mathrm{mL}^{-1}\end{array}$ & $0.005 \mathrm{mg} \mathrm{mL}^{-1}$ & {$[\mathrm{~S} 7]$} \\
\hline $\begin{array}{l}\text { Diffraction } \\
\text { grating } \\
\text { immunosensors }\end{array}$ & $\begin{array}{l}\text { H-IgG-responsive hydrogel } \\
\text { gratings }\end{array}$ & $13 \sim 53 \mathrm{nM}$ & $13 \mathrm{nM}$ & $\begin{array}{l}\text { This } \\
\text { work }\end{array}$ \\
\hline
\end{tabular}




\section{REFERENCES}

(S1)Nelson, J. T.; Kim, S.; Reuel, N. F.; Salem, D. P.; Bisker, G.; Landry, M. P.; Kruss, S.; Barone, P. W.; Kwak, S.; Strano, M. S. Mechanism of Immobilized Protein A Binding to Immunoglobulin G on Nanosensor Array Surfaces. Anal. Chem. 2015, 87, 8186-8193.

(S2)Wang, B. T.; Wang Q. An Interferometric Optical Fiber Biosensor with High Sensitivity for IgG/Anti-IgG Immunosensing. Opt. Commun. 2018, 426, 388-394.

(S3)Melnik, E.; Bruck, R.; Muellner, P.; Schlederer, T.; Hainberger, R.; Lämmerhofer, M. Human IgG Detection in Serum on Polymer Based Mach-Zehnder Interferometric Biosensors. J. Biophotonics 2016, 3, 218-223.

(S4)Wang, Q.; Wang, B. T. Surface Plasmon Resonance Biosensor Based on Graphene Oxide/Silver Coated Polymer Cladding Silica Fiber. Sensor. Actuat. B-Chem. 2018, 275, 332-338.

(S5)Wang, Y. Y.; Tang, L. Multiplexed Gold Nanorod Array Biochip for Multi-Sample Analysis. Biosens. Bioelectron. 2015, 67, 18-24.

(S6)Shi, S.; Wang L. B.; Su R. X.; Liu, B. S.; Huang, R. L.; Qi W.; He, Z.M. A Polydopamine-Modified Optical Fiber SPR Biosensor Using Electro-Less-Plated Gold Films for Immunoassays. Biosens. Bioelectron. 2015, 4, 454-460.

(S7)Islam, N.; Gurgel, P. V.; Rojas, O. J.; Carbonell, R. G. Use of a Branched Linker for Enhanced Biosensing Properties in IgG Detection from Mixed Chinese Hamster Ovary Cell Cultures. Bioconjugate Chem. 2019, 30, 815-825. 